\title{
Employees Competence Models on Impact to Performance KUD in Riau Province Indonesia
}

\author{
Eddy Irsan Siregar \\ Master of Management, Graduate School, University of Muhammadiyah Jakarta, Indonesia
}

\begin{abstract}
Cooperatives play an important role in the economic development of Indonesia because it can improve the welfare of the community and stronger cooperative members because they through its unique character, which is a combination of economic and social character. The purpose of this study was to determine the effect of competence for management and variety of products / services to the participation of members of the cooperative and its impact on the performance of KUD cooperatives in Riau Province. The object of this study is KUD Mekar Jaya namely large, KUD Makmur Lestari the medium and KUD Sumber Rezeki is a small cooperatives with the total number of its members as many as 1,290 people. The sampling technique using proportional random sampling technique. Research models using Structural Equation Modelling with the variables studied consisted of two exogenous variables and the intervening variables and the endogenous variable. Is the competence of the management of exogenous variables (X1) and variety of products / services (X2) and the intervening variable is the participation of members (X3), whereas exogenous variable is the performance of KUD (Y). The method used in this research is quantitative method. To process the data used path analysis method two steps with the help of soft ware SPSS 16. The results showed that there was a positive and significant effect on the competence of the management of the performance.
\end{abstract}

Keywords: competence of the management, variety of products / services, participation of members, the performance of KUD.

\section{Introduction}

Cooperative is the cooperation of several people to improve the economic value of the popularity of the company, founded by the appropriate ethics and mutual respect local culture well defined and principles, which include concern for the community (J.Curl, 2010). Cooperatives have a unique character, which is a combination of elements of economic and social elements. The unique character of this double establish a cooperative ideal and in fact the only vehicle to ensure equity. In addition to being the only way to bring poor citizens recognized legal entity, also provides employment to be earning better together to support the necessary services, cooperative community-based democracy, flexibility and involvement participatory which makes them suitable for improving community welfare (N Muhammed, 2012).

Birchall, J, 2004, concluded that the air-cooperative allows people to raise themselves out of poverty, then the cooperative also be a means for low- and middle-income people to achieve economic gains. Cooperatives are not designed as a poverty alleviation tool, but it can function positively, where a group of people can benefit individually economy when they can not achieve it.

KUD performance becomes important in order to achieve the purpose of establishing a cooperative, the welfare of the members. This performance can not be separated from the influence of various factors from the board itself in providing excellent service and competence as well as members from participating in awareness of cooperatives. As an institution engaged in the field of financial services, the cooperative will help ease the flow of money from one place to another, launch transaction between supply and demand, launched the procurement of capital investment and working capital to businesses that are categorized as priority or not a priority, all require the services cooperative.

In an effort to provide satisfactory services to members, has many cooperatives are competing to offer the advantages of their products or services to attract customers and trust to invest and jointly build a cooperative. To gain a competitive advantage on a global scale, in addition to the products or services of the cooperative also required to present or provide a quality service. The problems that arise in terms of service to the consumer either service a product or service is how to provide quality service and satisfying considering each cooperative has a characteristic or tersediri advantages in terms of products and services. Quality of service is solely given to the consumer / members, so that customer satisfaction can only be achieved by providing a good quality.

The level of consumer interest in services that they receive can be formed based on the experience and advice they receive. Consumers choose a service provider based on the ranking of interest. And after enjoying the services they tend to compare it with what they expect. When the services that they enjoy it turned out to be far below the services they expect, consumers will lose interest in the service provider. Conversely, if the services they enjoy meets or exceeds the level of interest, they would tend to reuse these services products.

Issues regarding the management of KUD a conversation, in which the board is one of the factors that affect the performance of KUD, besides other sections are also members. Problems are less competent 
administrators in managing the cooperative constraint. In addition the board is less good at providing services, so there is a tendency towards the participation of members of the cooperative to be low. Also from the members still felt that the awareness of members of the cooperative is still low due to lack of knowledge about cooperatives, and also board member less socialization to the existence of the cooperative.

The problems of this study are:

1. How does the competence of the management of the participation of members of KUD

2. How does the variety of products / services cooperative to the participation of members of KUD

3. How can the influence of competence of the management on the performance of KUD

4. How does the variety of products / services on the performance of KUD cooperatives.

5. How does the participation of members of the performance.

\section{Theoretical Review}

A. Performance. Understanding performance by Prawirosentono (2008) performance or the performance is the result of work that can be achieved by a person or group of people in an organization, in accordance with the powers and responsibilities of each, in an effort to achieve the goals of the organization in question legally, does not violate the law and in accordance with moral and ethical.

According to Robbins (2005: 218), is the result of individual work performance, behavior and characteristics. Results of tasks such as the amount produced, the amount of resources used, the cost per unit, sales volume, sales increase, accretion accounts, behaviors such as how to serve, leadership, sick leave, the presence and characteristics of such a good attitude, confidence and cooperation. Can be interpreted that the performance is not only measured on the results achieved, but also any person's behavior in carrying out the work and the attitude shown person to achieve work goals. Meanwhile Martoyo (2006), suggests that the performance is the result of the achievement of the implementation of the tasks assigned to each worker.

Based on the notions above it can be concluded that the performance is a result of the overall quality and quantity of work that has been done a clerk in achieving what the objectives of the organization. This is according to Bacal (2001) explains that the order of performance in accordance with the requirements, the need to implement performance management is communication ongoing between the manager and every employee, to clarify the responsibilities of work and to improve performance continuously ie through work planning, communication takes place continuously and evaluated through the collection of data and observations and documentation. Based on the above, it can be concluded that the performance of cooperatives is the result of the overall quality and quantity of work that has been done KUD board in achieving what the objectives of KUD. KUD performance dimensions are: 1) Productivity; 2) Quality of service; 3) Responsiveness; 4) Responsibility; and 5) Accountability.

B. Competence Management. According Nastiti (2007) competence is often associated with a sense of "capable" or qualified to do something or a job, for example in the management of human resources (HR), especially on career planning, employee will be promoted employees who are considered to have high competence, while employees the quality is not considered to have high competence (not able or qualified). For the foregoing, the word competence to discuss the results of the employee or a person's success in their job effectively (output models) and know him as competent. On the other hand, the word competence is often regarded as a required / desired to (be) doing a job on specific roles and positions (input model) referred to the competence / competency. Michael E. Porter (1997) describes basically grew from a value or benefit to a company creates for its buyers more than the costs the company to create. Value or benefit that is available is paid by the buyer, and superior value is derived from offering lower prices than competitors prices for equivalent benefits or offers unique benefits that exceed the price offered. The factors affecting the competitiveness among other things: technological factors, electoral competitors, segmentation, substitutions and strategy.

C. Variations Products / Services. Talking about the variety of products within an organization varies, but the concept of service becomes the main thing, according Moenir (2000: 16) is a process of using intellect, mind, senses and limbs with or without tools carried by someone to get something desirable either in the form of goods and services. Then Susilo (2001) stated that the ministry is an attempt to help or benefit to the public through the provision of goods or services required by them. In the public sector, the terminology of government services (government service) is defined as the delivery of services by government agencies through employees. Further disclosed that the state government system and become the foundation of service of the citizens in obtaining guarantees of their rights, the improvement of quality of service (quality of service) will be increasingly important. Request for public services will always increase both quality and quantity, along with increasing population, increasing social welfare and changes in a constantly changing environment. In order to meet the demands and expectations, the readiness and capability of personnel needs to be improved in order to avoid a gap between the demands and expectations of society on the one hand and capability of personnel in the implementation of service functions on the other. To eliminate / reduce this gap apparatus must have high professional skills constantly keep up with developments in society. In anticipation of such circumstances public 
bureaucracy should be prepared systematically by creating the institutional system of the apparatus, the staffing system and good management mechanism and integrated, so that in turn the apparatus is able and ready to face the demands of users of public services is increasing.

Based on the above opinion, it is clear it can be seen that the service or product variation is a form or type of services provided by the cooperative to its members in order to meet the needs of members. There are many opinions that provide an explanation about the size of a good service that can be provided to members as submitted by Soewarso (2002) gives an account of the quality of human resources related to the productivity of the organization if all employees are oriented to the market or consumers. Then Bambang (2001) considers several criteria need to be considered, namely: 1) Appropriate and relevant, meaning that the service must be able to meet the preferences, expectations and needs of individuals and communities; 2) Available and affordable, meaning that the service should be reachable by any person or group who get priority; 3 ) to ensure a sense of justice, that is open in giving treatment to an individual or group of people in the same state; 4) Acceptable, meaning that the service quality when viewed from a technical / how, quality, convenience, comfort, fun, reliable, fast, timely, responsive and humane; 5) Economical and efficient, meaning that from the user point of service can be reached through tariffs and taxes by all levels of society; 6) Effective means beneficial to users and all levels of society.

Variations of a given product cooperatives, among others related to the type of business that is given in the form of services such Waserda services and other provisions for members of the dimensions are 1) the ease, 2) fairness, 3) treatment of officers, 4) honesty.

D. Participation Members. The concept of participation by Marbun (2003) participation is a sense of involvement and commitment level of a person's mind and its thanks to donations so that they are responsible for his own work and join in efforts to achieve the target of an organizational goal. Dimensions of Participation are: 1) contributed to fend for themselves by utilizing KUD as a partner; 2) awareness of the high society and the state by handing over to the cooperative self-determination; 3 obligations as citizens responsible for paying deposits and obligations of members; 4) adherence to various regulations that have been established in the cooperative; and willingness to perform sacrifices demanded KUD in development together in the future.

Several previous studies such as Lilian Nurlina (2010) studied under the title "Relations with the level of participation of farmers cooperative members sustainability efforts". Faculty of Animal Husbandry, Padjadjaran University. Conclude that there is a positive relationship between the participation of members of the cooperative business continuity.

Siska Ismail, Yanti Saleh, Amelia Murtisari, 2013, KIM, Vol 1, No. 1, "The development strategy of Village Unit Cooperatives (KUD)" Thanks to the "Lake District Gorontalo". These results indicate that strategy is applied to the activities of Gorontalo Regency KUD Thanks to member enrollment strategy for the situation needs anggotaKartib Bayu (2006) "Effects of entrepreneurial attitude of the manager and the participation of members of the implementation of product marketing strategy and its implications on the performance of cooperative efforts". UNIKOM Scientific magazine Vol.8, No. 2, cooperative business performance superior realized if the positive attitude of entrepreneurial managers, the level of active participation and marketing strategies can be implemented properly.

Anggraini, Novi Hasti (2009: i) Analysis of factors affecting the cooperatives operation profit Servants in Surakarta in 2007. Masters thesis, University of March. The results showed that the number of members a significant effect on the number of Business at a significance level of 5\%, while the amount of their own capital and outside capital does not significantly influence the rate of $5 \%$. Can say that the competence of the management, the variety of products / services cooperatives and the participation of members have linkages with each other on the performance of KUD. Based on the above theory, the frame can be made of the following:

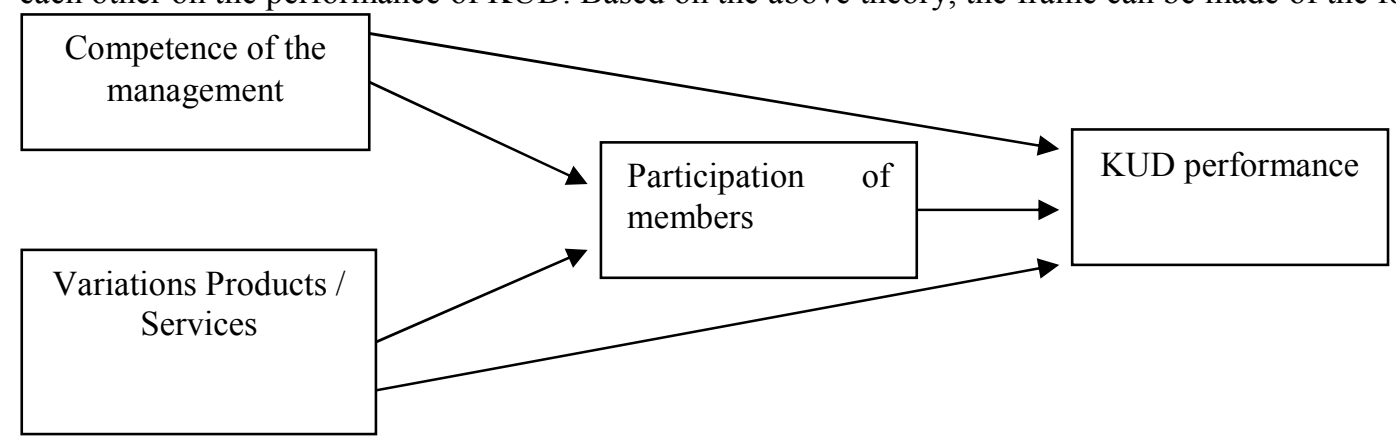

\section{Hypothesis}

Picture.1 Theoretical Framework

The research hypotheses as follows:

1. Influences of competence of the management of the participation of members. 
2. There varasi influence product / service cooperatives to the participation of members.

3 . There is a competence of the management influence on the performance of cooperatives.

4. There is a variation of the effect of the product / service cooperatives to cooperative performance.

5. There is the influence of the participation of members of the cooperative performance.

\section{RESEARCH METHODOLOGY}

This research uses quantitative methods, the research seeks to describe a symptom, events and happenings that become the center of attention for the analyzed between exogenous variables (independent variable), variable intervening and endogenous variables (the dependent variable) by using Structural Equation Modelling (SEM) and processed using path analysis (path analysis) and SPSS 16 soft ware.

Population and Sampling

The population in this study were all members of KUD in Riau Province totaling 16 units KUD and taken as many as 3 KUD is based on Law No. 17 Year 2000 on Income Tax KUD split into three groups, namely the group of cooperatives that have SHU less than Rp. KUD 50 million classified as small and not subject to corporate tax, then KUD which has SHU between Rp. 50 million s / d Rp. 100 million in the medium and KUD KUD SHU which has more than Rp. 100 million or large cooperatives. Defined KUD KUD Sawit Mekar Jaya namely large, namely KUD KUD Makmur Lestari medium, and KUD Source of Sustenance ie small cooperatives with the total number of members of the KUD third as many as 1,290 people. The sample is part of the number and characteristics possessed by the population. Given the relative number of population, defined in part as a sample. The sampling technique using proportional random sampling technique (Sugiyono, 2008). The sample size determined by using the formula slovin as follows:

$$
n=\frac{N}{1+N e^{2}} \quad n=\frac{1.290}{1+1.290 \times 1 \%^{2}} \quad n=\frac{1.290}{1+12.90} \quad n=\frac{1.290}{13,90}
$$

$\mathrm{n}=92,8=93$

For more details can be seen in the following table:

Table 3.1. Population and Sample

\begin{tabular}{|c|c|c|c|c|}
\hline No & KUD & Category & Population & Sample \\
\hline 1 & Mekar jaya & Big & 465 & 34 \\
\hline 2 & Makmur lestari & Moderate & 500 & 36 \\
\hline 3 & Sumber Rezeki & Small & 325 & 23 \\
\hline & Total & & 1.290 & 93 \\
\hline
\end{tabular}

Source: Data Processing, 2013

In this research will be conducted descriptive research with survey method. The draft instruments consisted of the variables, indicators and statement items of each variable. While the questionnaire used in this study. Data was collected by means of literature study, field research. Questionnaires were used to collect research data beforehand on test validity and reliability. Test the validity of the instrument aims to identify the accuracy and precision of the measuring instrument in performing its functions. While the reliability test results associated with accuracy problems (Suharsimi Arikunto, 2006)

Data were analyzed using path analysis techniques. Mechanical analysis of this path will be used to test the amount of the contribution shown by the path coefficients for each path diagram of a causal influence on the variables $\mathrm{X} 1, \mathrm{X} 2$, and $\mathrm{X} 3$ and the $\mathrm{Y}$ and impact, correlation and regression analysis which is the basis for the calculation of the path coefficients are then in its calculations using software with SPSS version 16 empirical Framework for a causal relationship between the tracks as follows: 


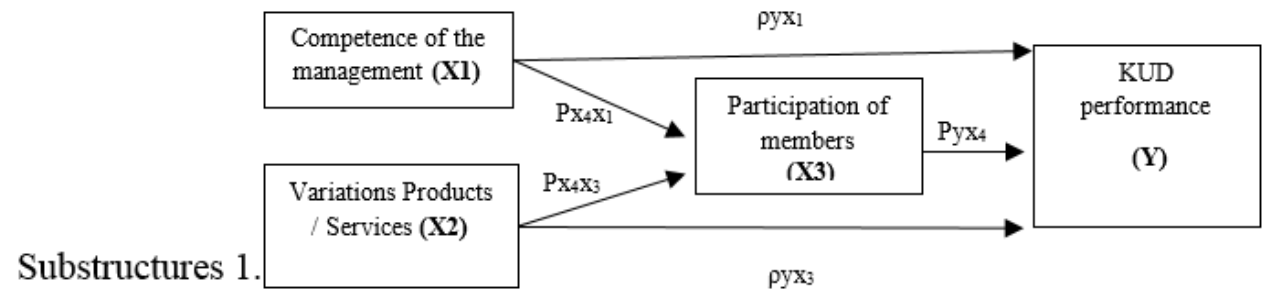

Figure 3.1. Relationships structure $\mathrm{X} 1, \mathrm{X} 2, \mathrm{X} 3, \mathrm{X} 4$ on $\mathrm{Y}$

Substructures 2

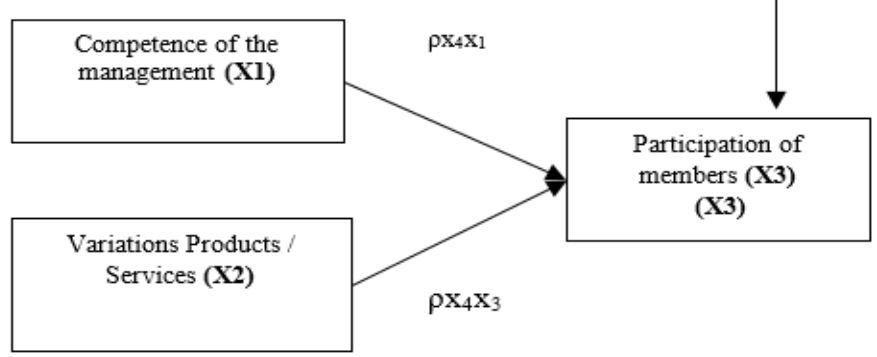

Figure 3.2. Relationships structure X1, X2, X3 against

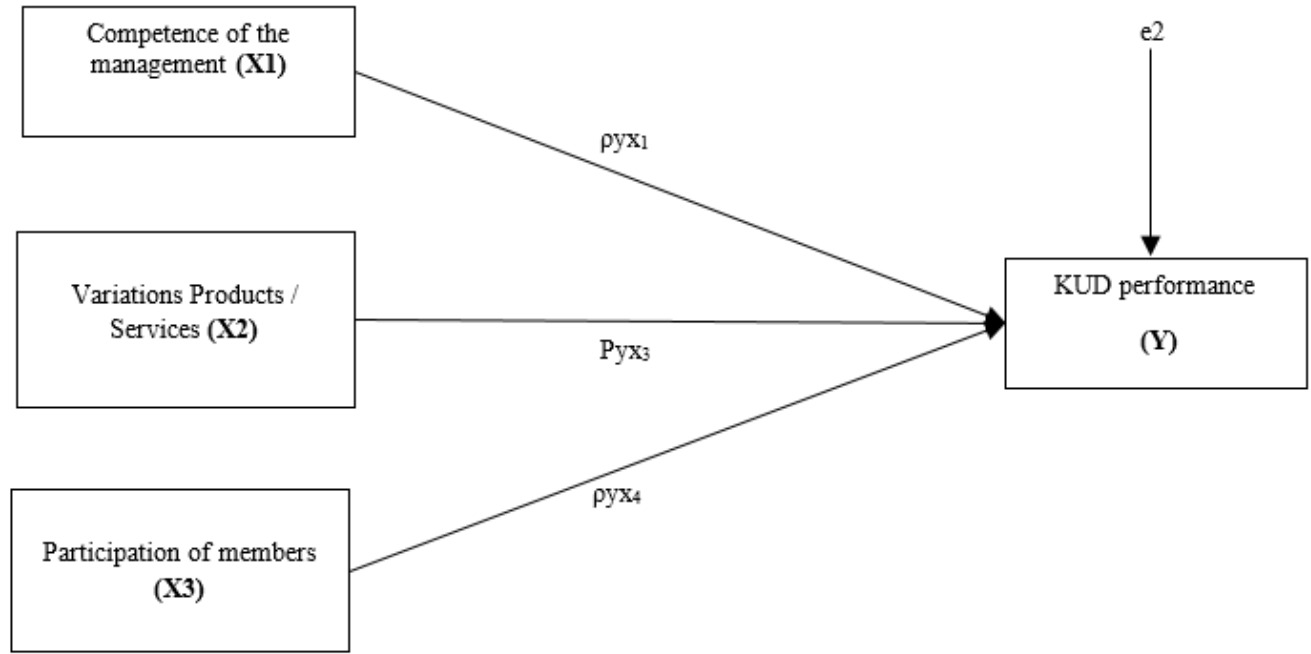

Figure 3.3. Relationships structure $\mathrm{X} 1, \mathrm{X} 2$, and $\mathrm{X} 3$ to $\mathrm{Y}$

\section{RESEARCH RESULT}

Sub-structure test 1

In table 4.1 Anova sub-structure 1 which shows the value of $\mathrm{F}$ as simultaneous testing between the competence of the management (X1) and variety of products (X2) on the Participation of members (X3). Significant test path analysis by comparing the probability value sig with a probability value of 0.05 with a basis for a decision as follows: if sig $\geq 0.05$ then Ho is accepted and Ha is rejected, it means insignificant. Conversely, if sig $\leq 0.05$ then Ho is rejected and Ha accepted, meaning significantly. 
Table 4.1. Anova substructure 1

ANOVA $^{b}$

\begin{tabular}{llrrrrr}
\hline Model & & Sum of Squares & df & Mean Square & F & Sig. \\
\hline 1 & Regression & 6373.194 & 3 & 2124.398 & 193.569 & $.000^{\mathrm{a}}$ \\
& Residual & 976.763 & 89 & 10.975 & & \\
& Total & 7349.957 & 92 & & & \\
\hline
\end{tabular}

a. Predictors: (Constant), Variations Products / Services, competence of the management

b. Dependent Variable: Participation of members

Coefficients in Table 4.2 is a sub-structure 1 which shows the value of $t$ as an individual test between the competence of the management (X1) and variety of products (X2) on the Participation of members (X3). Significant test path analysis by comparing the probability value sig with a probability value of 0.05 with a basis for a decision as follows: if sig $\geq 0.05$ then $\mathrm{Ho}$ is accepted and $\mathrm{Ha}$ is rejected, it means insignificant. Conversely, if sig $\leq 0.05$ then Ho is rejected and Ha accepted, meaning significantly.

Table 4.2. Coefficients Substructures 1

Coefficients $^{\mathbf{a}}$

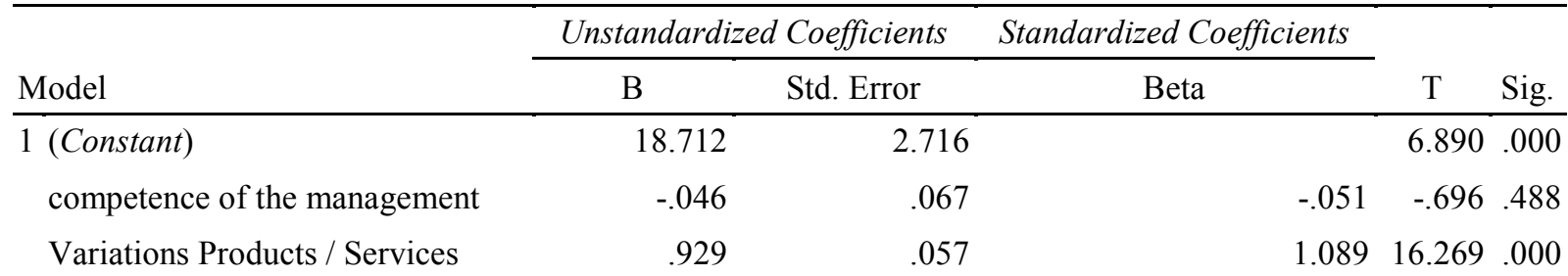

a. Dependent Variable: Participation of members

In Table 4.3 is a summary of sub-structure 1 which shows the coefficient of determination or influence ( $\mathrm{R}$ square) $=>\mathrm{R}=0863$ which bermakkna that the competence of the management, the variety of products / services cooperative strong influence on the participation of members of KUD.

Tabel 4.3. Summary Sub-structure 1

\section{Model Summary}

\begin{tabular}{|c|c|c|c|c|}
\hline Model & $\mathrm{R}$ & $R$ Square & Adjusted R Square & Std. Error of the Estimate \\
\hline 1 & $.931^{\mathrm{a}}$ & .867 & .863 & 3.31283 \\
\hline
\end{tabular}

a. Predictors: (Constant), Variations Products / Services, competence of the management

b. Dependent Variable: Participation of members

Simultaneous testing

Test overall

Statistical hypothesis is formulated as follows:

Ha: $\rho \times 3 \times 1=\rho \times 3 \times 2 \neq 0$

Ho: $\rho \times 3 \rho \times 3 \times 1=\times 2=0$

The hypothesis in the form of a sentence:

$\mathrm{Ha}$ : competence of the management (X1) and variety of products (X2) affect the participation of members (X3).

Ho: competence of the management $(\mathrm{X} 1)$ and variety of products (X2) does not affect the participation of members (X3).

From Anova table obtained $\mathrm{F}$ value of 193.569 with a probability value $(\mathrm{sig})=0.000$, because $\operatorname{sig}<0.05$, then the decision is Ho is rejected, meaning that the competence of the management, and a variety of products / services cooperative significant effect on the participation of members of KUD. Thus testing can be done individually or resumed.

Testing of individual sub-structures 1

Competence of the management significantly influence the participation of members

Test individually coefficients sub-structure 1 . The research hypotheses to be tested is formulated into a statistical hypothesis as follows:

Ha: $\rho \times 4$ x $1>0$

Ho: $\rho \times 4 \times 1=0$

The hypothesis in the form of a sentence:

Ha: Competence administrators significantly affect the participation of members 
Ho: Competence board does not significantly affect the participation of members

Individually statistical test used was $t$ test obtained by value $t(X 1)=-0696$. Furthermore, to determine the significance of the analysis of the path between the probability values sig compare with probability value 0,488 with the basis for a decision as follows:

- If the probability value sig probability $\geq 0.05$ then Ho is accepted and Ha is rejected, it means insignificant.

- If the probability value sig probability $\leq 0.05$ then Ho is rejected and Ha accepted, meaning significantly.

It is seen that in a significant column in the table coefficients sub-structure 1 obtained sig 0,488 . Sig $0.488>0.05$, then Ho is accepted and Ha rejected, meaning that the competence of the board does not significantly influence the participation of members of KUD. This is because administrators and employees are less concerned about the members who enter the product key member of KUD.

Variations of products / services have a significant effect on the participation of members

Test individually coefficients shown in the table sub-structure 1. The research hypotheses to be tested is formulated into a statistical hypothesis as follows:

Ha: $\rho X 4$ X $3>0$

Ho: $\rho \mathrm{X} 4 \mathrm{X} 3=0$

The hypothesis in the form of a sentence:

Ha: Variations of products / services have a significant effect on the participation of members

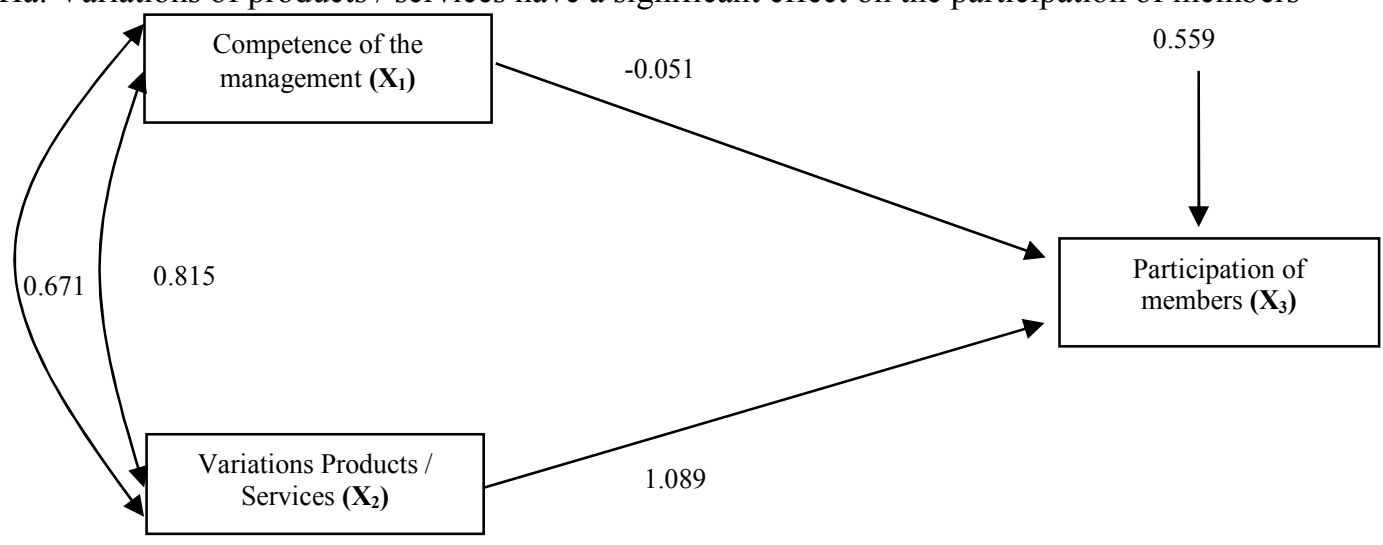

Figure 4.1. : Sub-Structure Diagram Line 1

\section{Sub Structure 2}

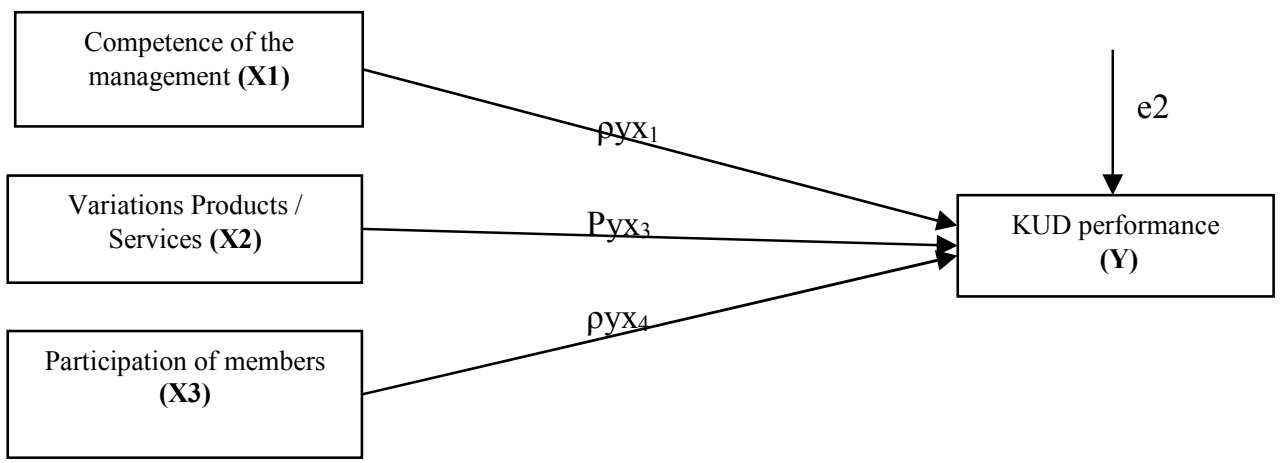

Figure 4.2: Sub-Structure Diagram Line 2

In Table 4.4 Anova sub-structure 2 which shows the value of $\mathrm{F}$ as simultaneous testing between the competence of the management, the variety of products / services cooperatives and the participation of members on the performance of cooperatives in the province of Riau. Significant test path analysis by comparing the probability value sig with a probability value of 0.05 with a basis for a decision as follows: if $\operatorname{sig} \geq 0.05$ then Ho is accepted and $\mathrm{Ha}$ is rejected, it means insignificant. Conversely, if sig $\leq 0.05$ then Ho is rejected and Ha accepted, meaning significantly. 
Tabel 4.4. : Anova Sub-Struktur 2

ANOVA $^{b}$

\begin{tabular}{|c|c|c|c|c|c|c|}
\hline \multicolumn{2}{|c|}{ Model } & \multirow{2}{*}{$\begin{array}{r}\text { Sum of Squares } \\
6738.679\end{array}$} & \multirow{2}{*}{$\frac{\mathrm{df}}{4}$} & \multirow{2}{*}{$\frac{\text { Mean Square }}{1684.670}$} & \multirow{2}{*}{$\frac{F}{135.899}$} & \multirow{2}{*}{$\frac{\text { Sig. }}{.000^{\mathrm{a}}}$} \\
\hline 1 & Regression & & & & & \\
\hline & Residual & 1090.891 & 88 & 12.396 & & \\
\hline & Total & 7829.570 & 92 & & & \\
\hline
\end{tabular}

a. Predictors: (Constant), Participation of members, competence of the management, Variations Products / Services

b. Dependent Variable: KUD performance

In Table 4.5 are coefficients sub-structure 2 which shows the value of $t$ as an individual test between the competence of the management, the variety of products / services cooperatives and the participation of members on the performance of cooperatives in the province of Riau. Significant test path analysis by comparing the probability value sig with a probability value of 0.05 with a basis for a decision as follows: if $\operatorname{sig} \geq 0.05$ then Ho is accepted and Ha is rejected, it means insignificant. Conversely, if sig $\leq 0.05$ then Ho is rejected and Ha accepted, meaning significantly.

Table 4.5. : Coefficients Sub-structure 2

Coefficients $^{\mathbf{a}}$

\begin{tabular}{|c|c|c|c|c|c|c|}
\hline \multirow[b]{2}{*}{ Model } & \multicolumn{2}{|c|}{ Unstandardized Coefficients } & \multicolumn{2}{|c|}{ Standardized Coefficients } & \multirow[b]{2}{*}{$\mathrm{t}$} & \multirow[b]{2}{*}{ Sig. } \\
\hline & B & Std. Error & Beta & & & \\
\hline 1 (Constant) & 7.363 & 3.574 & & & 2.060 & .042 \\
\hline competence of the management & .419 & .071 & & .448 & 5.894 & .000 \\
\hline Variations Products / Services & .260 & .121 & & .295 & 2.149 & .034 \\
\hline Participation of members & .008 & .113 & & .008 & .071 & .943 \\
\hline
\end{tabular}

a. Dependent Variable: KUD performance

In Table 4.6 is a summary of sub-structure 2 which shows the coefficient of determination or influence ( $\mathrm{R}$ square $)=>\mathrm{R}=0854$ means that there is a strong relationship between the competence of the management, the variety of products / services cooperatives and the participation of members on the performance of cooperatives in the province of Riau.

Table 4.6. Summary 2 Sub-structure

Model Summary ${ }^{b}$

\begin{tabular}{lrrrr}
\hline Model & $\mathrm{R}$ & $R$ Square & Adjusted $R$ Square & Std. Error of the Estimate \\
\hline 1 & $.928^{\mathrm{a}}$ & .861 & .854 & 3.52086 \\
\hline
\end{tabular}

a. Predictors: (Constant), Participation of members, competence of the management, Variations Products / Services

b. Dependent Variable: KUD performance

The answer to the problem of these studies are summarized by $4: 16$ the following table:

Table 4.7. The path coefficients, direct effect, indirect effect, total effect and the influence of joint competence of the management (X1), the variety of products / services (X2) and the participation of members (X3) on the performance of KUD (Y)

\begin{tabular}{lccccc}
\hline \multirow{2}{*}{ Variabel } & \multirow{2}{*}{ Regression coefficients } & \multicolumn{3}{c}{ Influence } & \\
\cline { 3 - 5 } & & Directly & Indirectly through & \multirow{2}{*}{ Total } & simultaneous effect $\left(\mathrm{R}_{\mathrm{yx}}\right)$ \\
\hline $\mathrm{X} 1$ & 0,419 & 0.448 & 0,0004 & 0,4484 & - \\
$\mathrm{X} 2$ & 0,260 & 0.295 & 0.009 & 0.304 & - \\
$\mathrm{X} 3$ & 0.008 & 0.008 & - & - & - \\
$\varepsilon_{1}$ & 0,559 & 31,25 & - & - & - \\
$\varepsilon_{2}$ & 0,373 & 13,91 & - & - & 0,861 \\
$\mathrm{X}_{1}, \mathrm{X}_{2}, \mathrm{X}_{3}$ & - & - & - & - &
\end{tabular}

From the table above it can be seen the influence of the variable direct competence of the management 
on the performance of 0.448 , while the indirect effect is through the participation of members of 0.0004 and a direct influence on the performance variables of product variations of 0.295 , while the indirect effect is through the participation of members of 0.009 , Thus the known pathways that provide a greater influence on performance is variable products through a variety of member participation.

Based on the research results, that hypothesis testing is done, obtained evidence that the competence of the management negative and not significant to the participation of members, the variety of products / services positive and significant impact on the participation of members, the competence of the board positive and significant impact on the performance of KUD, variety of products / services and significant positive effect on the performance and participation of members of cooperatives and not significant positive effect on the performance of KUD. The explanation of these facts will be discussed in detail as follows:

Against the influence of Competence Board Member Participation.

Based on the survey results revealed that the competence of the management and no significant negative effect on the participation of members it can be shown with sig of 0.488 and the value of the effect of -0.051 . Values influence competence of the management and no significant negative effect on the participation of members of this means that the higher the competence of the management, the participation of members of the lower. Influence of -0.051 , which means if the unit improved competence of the management of the unit while the other variable in this case is the variety of products / services remain the participation of members of the unit will decrease by 0.051 .

Competence of the management is a skill or readiness administrators manage cooperatives, based on the results of this research is that 1). Some members of KUD assess the management is quite capable of doing introspection manage cooperatives in improving the competence of the future, then also quite prepared to admit mistakes done for the sake of future improvement, enough to be able to accept criticism from members and quite willing to learn from past mistakes in fixing KUD forward. So there is a tendency member give greater confidence to the board in the care of the KUD. 2). Members also assume caretaker KUD is already quite capable of organizing a meeting of members, is quite exposed weaknesses in its staff, quite confronting to members in its staff and enough trying to find solutions to the problems encountered so that the participation of members of the cooperative entrusted to the existing board. 3). Some members consider the board is already quite capable in taking decisions by consensus, which made a joint decision shall be fully supported, a position within the organization did not guarantee the quality of the idea that the participation of members of the KUD KUD has been submitted to the board. 4). Some members assume management board did a pretty open and apply in accordance with the ethics to tell the truth and provide equal treatment for all employees so that members entrust the stewardship and management of KUD to the board. 5). Some members of the committee consider quite believe in the principle of hard work, where high productivity is something to be proud, has a long-term commitment, if there are problems with the resignation of career better than dismissal so that the work involved to the members entrusted to the board. From the above description, it can be seen that the competence of the management negatively affect the participation of members, where the competent management or able to carry out the management of the members do not want to interfere in the management of increasingly well in their criticism and suggestions. Most items are lower in the competence of the management board on the application of idealism in implementing the management board. Where is basically a good steward is a caretaker who would not make memintarkan member KUD KUD members do not even want this berpartisipasi.Hal, contrary to the opinion of Robbins (2005) which says that a good steward is a caretaker who can or can afford memintarkan members. This means that existing cooperative management in Riau province is still not in either category.

Influence Varasi Products / Services Cooperative Members Against Participation.

Based on the results of data processing is known that the variety of products / services and significant positive effect on the participation of members it can be shown with sig of 0.000 and the value of the effect of 1,089 . Values influence of variations of products / services and significant positive effect on the participation of members of members of this means that a wider variety of products or services, the cooperative participation of members of the higher. Influence of 1,089 units, which means when the variety of products or services increased one unit while the other variable in this case is the competence of the management variables remain the participation of members will be increased by 1,089 units.

Variations of products / services cooperative is a form or type of services provided by the cooperative to its members in order to meet the needs of members. Based on the survey results revealed that the variety of products produced, as follows 1). Some members of their cooperatives hold enough ease the availability of all the needs of members of the KUD oil with particular regard to the needs of members. So that members of the cooperative to be pleased in getting service and meet their needs. 2). Members consider the fairness of providing services that are a step or procedure determination by the board of management of cooperatives which correspond to real conditions on the ground so that members of KUD be happy to receive services provided KUD. 3). Members officer considers reasonably their treatment is a form of treatment that is not favoritism 
officer in treating each member of KUD thus welcomes the services provided. 4). Members consider their honesty is a form of what is given in the officer serving member of KUD oil so as to provide confidence in the service to members.

From the description it can be seen that the variations of products / services provide positive and significant impact on the participation of members of KUD. This is in line with the results of the study Siska Ismail, Yanti Saleh, Amelia Murtisari (2013) that take advantage of business units that are managed by looking at market opportunities for commodities produced cooperatives, improve the quality of service to members, enhance the business units that are managed in order to reduce competition more stringent, increasing the coaching and training of government employees and cooperative management, hiring back employees in accordance with the competencies required of cooperatives, in order to optimize the computerized system efensiensi and effectiveness of operational activities KUD Thanks, improve internal cooperation in the operational management of the cooperative.

Effect of Competence Management Performance Against KUD.

Based on the results of data processing in mind that the competence of the management and significant positive effect on the performance of KUD, it can be shown with sig 0,000 and the value of the effect of 0.448 . Values influence competence of the management and significant positive effect on the performance of KUD members of this means that the higher the competence of the management, the performance of KUD higher. Influence of 0.448 units, which means when the competence of the management increased the unit while the other variable in this case is variable variation of products / services remains the performance of KUD will increase by 0.448 units.

Results of research on the competence of the board can be seen that is already quite good management should be able to criticize themselves, be able to recognize, accept and learn from past mistakes. Then is good enough in encouraging the confrontation were open and constructive and is seen as a method of problem solving, decision by consensus, the joint decision made must be fully supported, a position within the organization did not guarantee the quality of the ideas are good enough and also an open management and apply appropriate ethics by telling the truth and giving equal treatment for all employees and already believe in the principle of hard work, where high productivity is something to be proud, has a long-term commitment, if there are problems with the resignation of career better than dismissal.

This affects the performance of KUD in running the cooperative stewardship. The results are consistent with what is said to be Made Between, Guntur Komenaung Anderson (2007) (i) that the internal factors such as administrators and employees have a direct impact of 0.42 and the indirect effect of 0.00 . So in total internal factors affect the performance of KUD of 0.42 , (ii) external factors have a direct impact of 0.69 and 0.00 indirect influence. So in total external factors affect the performance of KUD of 0.69 .

Effect of Variations Products / Services Cooperative Performance Against KUD.

Based on the results of data processing is known that the variety of products / services and significant positive effect on the performance of KUD, it can be shown with sig at 0.011 and 0.295 of the value effect. Values influence of variations of products / services and significant positive effect on the performance of KUD members beravariasi this means that the product or service, the higher the performance of KUD. Influence of 0.295 units, which means if the variations of products / services increased one unit while the other variable in this case is the variable remains the competence of the management performance of KUD will increase by 0.295 units.

Results of research on the variety of products / services Cooperative is a form or type of services provided by the cooperative to its members in order to meet the needs of members. Known to have quite the ease of the availability of all the needs of members of the KUD oil with particular regard to the needs of members. Then the reasonableness of the determination steps or procedures of maintenance by the board KUD in accordance with the real conditions on the ground, their treatment officer is a form of treatment officers who do not favoritism in treating each member cooperatives and their honesty is a form of what is given officers in serving members KUD.

This makes the performance of KUD be good, the results of this study are consistent with what was said Kartib Bayu (2006) Participation tendency is already active. Implementation of the marketing strategy is not a good tendency. Performance at KUD cooperative efforts in West Java has been good tendency. The attitude of entrepreneurial managers are intimately connected with the participation of members. The attitude of entrepreneurial managers and participation of members of both partially and simultaneously influence the implementation of marketing strategies. The attitude of entrepreneurial managers and participation of members of both partially and simultaneously influence the performance of a cooperative effort. Implementation of marketing strategies affect the performance of cooperative efforts.

Member Participation Influence on Performance of KUD.

Based on the results of data processing in mind that the participation of members and no significant positive effect on the performance of KUD, it can be shown with sig at 0.943 and 0.008 of the value effect. Values influence member participation and no significant positive effect on the performance of KUD members of this means that the higher the participation of members of the higher performance of KUD. Influence of 0,008 units 
which means that if the participation of members increased by one unit while the other variable in this case is variable competence of the management and variety of products remains the performance of KUD will increase by 0,008 units.

Based on the results of research on the participation of members is one way to motivate that have characteristics other than the other in order to participate in the activities of cooperatives where members sometimes helped to fend for themselves by utilizing KUD as a partner. Also there are some who have awareness of high society and the state by handing over to the cooperative self-determination. Obligations as citizens responsible for paying deposits and obligations of the members enough to walk and their adherence to various regulations that have been established in the cooperative as well as their willingness to make the ultimate sacrifice demanded KUD in the joint development forward so that the performance of KUD improved but not real. The results are consistent with research Anggraini, Novi Hasti (2009: i) the results showed that the number of members a significant effect on the number of Business at a significance level of $5 \%$, while the amount of their own capital and outside capital does not significantly influence the rate of $5 \%$.

\section{Conclusions and Recommendations}

The conclusion that can be drawn from this study are as follows:

1. Competence board and no significant negative effect on the participation of members it can be shown with sig of 0.488 and the value of the effect of -0.051 . Values influence competence of the management and no significant negative effect on the participation of members.

2. Variation products / services and significant positive effect on the participation of members it can be shown with sig of 0.000 and the value of the effect of 1,089 . Values influence of variations of products / services and significant positive effect on the participation of members of members

3. Competence board positive and significant effect on the performance of KUD, it can be shown with sig of 0.000 and the value of the effect of 0.448 . Values influence competence of the management and significant positive effect on the performance of KUD.

4. Variations of products / services and significant positive effect on the performance of KUD, it can be shown with sig at 0.011 and 0.295 of the value effect. Values influence of variations of products / services and significant positive effect on the performance of KUD.

5. Participation of members and no significant positive effect on the performance of KUD, it can be shown with sig of 0.034 and the value of the effect of 0.008 . Values influence member participation and no significant positive effect on the performance of KUD.

\section{SUGGESTION}

It is recommended that

1. In a subsequent study using a broader research object, for example for the entire island of Sumatra or even the whole of Indonesia.

2. Officials KUD preferably selected from among educated so that performance can be optimized.

\section{Referencess}

Anggraini, Novi Hasti. (2009). Analysis of factors affecting operating results cooperative servants in the city of Surakarta in 2007. Masters thesis. Surakarta: University of March

Between, Made., \& Anderson Guntur Komenaung. (2007). Performance village unit cooperatives in the province bali: structural equation model approach. Soca Journal, Vol. 7. No. 3.

Arikunto, Suharsimi. (2006). A research procedure practice approach. Jakarta: Rineka Reserved

Bacal, Robert. (2001). Performance management. Surya Dharma interpreter and Yanuar Irwan. Jakarta: Gramedia Pustaka Utama

Bambang. (2001). The responsiveness and accountability of the public sector. Journal of Public Administration. Volume 1. No. March 2, 2001 Malang: FIA Unibraw.

Bayu, Kartib. (2006). Effect of entrepreneurial attitude of the manager and the participation of members of the implementing product marketing strategy and its implications for the performance of a cooperative effort. Scientific magazine Vol.8 UNIKOM. No. 2,

Birchall, J. 2004. Cooperatives and the Millennium Development Goals. Geneva: International Labour Organization

Curl, J, 2010. The cooperative movement in the 21 st century affinities: Journal of Radical Theory, Culture, and Action.

Hardjosoedarmo, Soewarso. (2002). Total quality management. Yogyakarta: Andi Offset.

Ismail, Siska., Yanti Saleh \& Amelia Murtisari. (2013). Cooperative development strategy Unit Desa (KUD) "Thanks". KIM, Vol 1. No. 1, Lake District Gorontalo

Marbun, B.N. (2003). Management dictionary. Jakarta: Pustaka Sinar Harapan. 
Martoyo, Susilo. (2006). Workforce management in the design and utilization development of elements of the workforce. Bandung: Sinar Baru.

Moenir. (2000). The management of public services in Indonesia. Jakarta: Earth Literacy.

Mohammed. N 2012, Role of Cooperatives in expanding the access of rural women to production resources in parts of Kano and Jigawa States. Academic Research International, 3 (3) (2012) 409-416.

Nurlina, Francine. (2010). The relationship with the farmer participation rate corporate sustainability members of the cooperative. Bandung: Faculty of Animal Husbandry, Padjadjaran University.

Porter, Michael E. (1997). Competitive strategy: techniques to analyze the industry and competitors. Translation Agus Maulana. Jakarta: publisher.

Prawirosentono, Suryadi. (2008). Policies employee performance. Yogyakarta: BPFE.

Proborini, Dyah Nastiti. (2007). The performance evaluation of the provision of water services system piping in the small town. Bandung: Department of Civil Engineering Faculty of Engineering and Built Environment planning ITB

Robbins, Sthepens. (2005). Organizational behavior. Translation Team Index. Jakarta: Index -Garamedia.

Susilo. (2001). Administration of public services: an initial conversation. journal Administration Country Volume 1 No. March 2, 2001 Malang: FIA Unibraw.

Tika, Moh. Pabundu. (2008). Organizational culture and performance improvement company. Print Second. Jakarta: PT. Earth Literacy. 